\title{
DEEP SURGICAL SITE INFECTIONS;
}

DETERMINE THE PREVALENCE OF DEEP SURGICAL SITE INFECTIONS (DSSIS) IN PATIENTS TREATED LAPAROTOMY PROCEDURE WITH OR WITHOUT POST-OPERATIVE WOUND IRRIGATION.

1. FCPS (General Surgery), MCPS Assistant Professor

Department of Surgical Unit-1, Ghulam Muhammad Mahar Medical College, Sukkur.

2. FRCS, DMRT

Assistant Professor

Department of Surgery Unit-3 Lahore General Hospital, Lahore.

3. FCPS (General Surgery)

Assistant Professor

Department of General Surgery College of Medicine \& Dentistry University of Lahore/Nawaz Sharif

Social Security Hospital, Multan Road, Lahore.

\section{Correspondence Address:}

Dr. Shahid Hussain Mirani

Department of Surgical Unit-1,

Ghulam Muhammad Mahar Medical

College,

Sukkur.

srgmirani@hotmail.com

Article received on:

29/05/2018

Accepted for publication:

20/10/2018

Received after proof reading:

23/02/2019

\section{Shahid Hussain Mirani ${ }^{1}$, Abdul Waheed Khan ${ }^{2}$, Ahmad Raza Nsar ${ }^{3}$}

ABSTRACT... Background: A surgical incision in the abdominal cavity (laparotomy surgery) is the most common procedure in surgical departments. Post-operative wound irrigation is very helpful method for surgeons to diagnose the surgical infections and to decrease the length of stay at hospital. Objectives: To determine the prevalence of deep surgical site infections in patients treated laparotomy procedure with or without post-operative wound irrigation. Study Design: Comparative control trial, observational study. Setting: Ghulam Muhammad Mahar Medical College Hospital, Sukkur. Period: $1^{\text {st }}$ January 2016 to $31^{\text {st }}$ December 2017. Material and Methods: Three hundred and thirty patients of both genders who had treated laparotomy because of intra-abdominal cavity and due to perforated appendix, examined TB, typhoid history, clinical treatments were included. All patients were divided into two groups with or without post-operative wound irrigation to examine the frequency of DSSIs in patients at third and seventh day of laprotomy treatment. Results: There were $180(54.55 \%)$ were men and 150 $(45.45 \%)$ patients were women. $50(15.15 \%)$ patients having ages of $<20$ years, $110(33.33 \%)$ patients were aged between 20 to 29 years, $130(39.39 \%)$ patients were aged between 30 to 39 years, $25(7.58 \%)$ patients having ages of 40 to 49 years and $15(4.54 \%)$ patients were ages $>49$ years. Hospital stay of patients was recorded from 2 to 10 days, 237 (71.82\%) patients having stay at hospital were 2 to 4 days, $63(19.09 \%)$ patients stay were 5 to 7 days while $30(9.10 \%)$ patients stay were $>7$ days. Out of all the 330 patients, 47 (14.24\%) patients found surgical site infections on $3^{\text {rd }}$ days, $43(13.03 \%)$ found DSSIs on $5^{\text {th }}$ day and $45(13.64 \%)$ patients had deep surgical site infections on $7^{\text {th }}$ day after laparotomy treatment. DSSIs on $3^{\text {rd }}$ days was noted in $23(6.97 \%)$ patients with Postoperative wound irrigation and 24 (7.24\%) without PO wound irrigations, $22(6.67 \%)$ found DSSIs with wound irrigations and $21(6.37 \%)$ without wound irrigations, while on $7^{\text {th }}$ day 21 and 24 patients had observed deep surgical site infections after operation. Conclusion: There is no major difference observed in prevalence of DSSIs whether performing post operative wound irrigation or do not performing PO wound irrigations after laparotomy procedure. Thus we concluded that the PO wound irrigations is not useful method to decrease the rate of DSSIs on $3^{\text {rd }}, 5^{\text {th }}$ and seventh day of after operation.

Key words: Deep Surgical Site Infections, Laprotomy, Post-Operative Wound Irrigation.

Article Citation: Mirani SH, Khan AW, Nsar AR. Deep surgical site infections; determine the prevalence of deep surgical site infections (DSSIS) in patients treated laparotomy procedure with or without post-operative wound irrigation. Professional Med J 2019; 26(3):484-487.

DOI: $10.29309 / \mathrm{TPMJ} / 2019.26 .03 .3258$

\section{INTRODUCTION}

Post-operative wound irrigation procedure of the abdominal cavity after surgical incision of abdomen (Laprotomy) has been performing since from many decades. As per the British Surgeon Law Tait, ${ }^{1}$ when in doubt, surgical wound irrigation is very useful to clear the doubt. ${ }^{2,3}$ Now a days, a surgical incision into the abdominal cavity (laprotomy) procedure/treatment is commonly performing in surgical departments, but it is very difficult for surgeons to choose the post-operative wound irrigation procedure due to the risk of increasing surgical site infections. Post-operative wound irrigations can helps the surgeons to diagnose the infection and to lessen the morbidity, but post-operative wound irrigations can cause the DSSIs. ${ }^{4-6}$ Deep surgical site infections is the most common morbidity found in patients who has treated with laprotomy treatment and it can cause the delay in healing wound, increase in infections, increase in treatment cost and time loss of expertise due to the long stay at hospital. ${ }^{7}$ 
In Pakistan, many studies has been conducted to evaluate the frequency of DSSIs and the results shows that rate of surgical site infection (SSIs) are $13 \%,{ }^{8}$ and these results are higher than the western countries. ${ }^{6}$ In USA the SSIs rate is $1.9 \%$.

Recently, many of international researches regarding DSSIs resulted $14.5 \%$ to $25 \% .^{9,10}$ Many other researches shows that an increase duration of hospital stay of patients are 6 to 25 days due to the DSSIs. ${ }^{11}$ In Germany, approximately one million extra days of hospital stay and an extra cost of approx three billion/year was estimated due to post-operative surgical site infections. ${ }^{12}$ Deep surgical site infections cause the considerable alarming in all surgical intercession. Abdominal infections are the most frequent morbidities found in Pakistan due to the lack of better techniques and medication to control the rate of surgical site infections, intestinal leakage and post-operative adhesion and it may cause to increase the ratio of deep surgical site infections.

In our surgical departments, Intra-operative wound irrigation method is commonly used. Current study was carried out to evaluate the prevalence of DSSIs with or without post-operative wound irrigations (POD) and to observe how this procedure is useful to reduce the DSSIs rate.

\section{MATERAILS AND METHODS}

This comparative randomised control trial, observational study was carried out at Ghulam Muhammad Mahar Medical College Hospital, Sukkur from $1^{\text {st }}$ January 2016 to $31^{\text {st }}$ December 2017. Three hundred and thirty patients of both genders who had treated laparotomy because of intra-abdominal cavity and due to perforated appendix, TB, typhoid history, clinical treatments were included. All patients were divided into two groups with or without post-operative wound irrigation to examine the frequency of DSSIs in patients at third, 5th and seventh day of laprotomy treatment with ages $<20$ to 60 years. Patients having other infections, successful appendicitis treatment, $1 \mathrm{~b}$ day stay at hospital were excluded in this study.

Data was analyzed by SPSS software 17.0. Chi square test was done to examine the difference in both groups with or without post-operative wound irrigations. P-value $<0.05$ should be considered significantly.

\section{RESULTS}

Out of 330 patients, 180 (54.55\%) were men and 150 (45.45\%) patients were women. 50 (15.15\%) patients having ages of $<20$ years, 110 (33.33\%) patients were aged between 20 to 29 years, 130 (39.39\%) patients were aged between 30 to 39 years, $25(7.58 \%)$ patients having ages of 40 to 49 years and 15 (4.54\%) patients were ages $>49$ years. Hospital stay of patients was recorded from 2 to 10 days, $237(71.82 \%)$ patients having stay at hospital were 2 to 4 days, 63 (19.09\%) patients stay were 5 to 7 days while $30(9.10 \%)$ patients stay were $>7$ days (Tables-I to IIII).

Out of all the 330 patients, 47 (14.24\%) patients found surgical site infections on 3rd days, 43 (13.03\%) found DSSIs on 5th day and 45 (13.64\%) patients had deep surgical site infections on 7th day after laparotomy treatment. DSSIs on 3rd days was noted in $23(6.97 \%)$ patients with Postoperative wound irrigation and 24 (7.24\%) without PO wound irrigations, on fifth day 22 $(6.67 \%)$ found DSSIs with wound irrigations and $21(6.37 \%)$ without wound irrigations, while on 7th day $21(6.37 \%)$ and $24(7.24 \%)$ patients had observed deep surgical site infections after operation. There is no significant difference between the both groups $(P>0,05)$ [Table-IV].

\begin{tabular}{|l|c|c|}
\hline \multicolumn{1}{|c|}{ Sex } & No. & $\%$ \\
\hline Men & 180 & 54.55 \\
\hline Women & 150 & 45.45 \\
\hline
\end{tabular}

Table-I. Gender wise distribution

\begin{tabular}{|c|c|c|}
\hline Age (years) & No. & $\%$ \\
\hline$<20$ & 50 & 15.15 \\
\hline $20-29$ & 110 & 33.33 \\
\hline $30-39$ & 130 & 39.4 \\
\hline $40-49$ & 25 & 7.58 \\
\hline$>49$ & 15 & 4.54 \\
\hline \multicolumn{2}{|c|}{ Table-II. Age-wise distribution of patients } \\
\hline
\end{tabular}

\begin{tabular}{|l|c|c|}
\hline Hospital stay (days) & No. & $\%$ \\
\hline $2-4$ & 237 & 71.82 \\
\hline $5-7$ & 63 & 19.09 \\
\hline$>7$ & 30 & 9.09 \\
\hline \multicolumn{2}{|c|}{ Table-III. Hospital stay of patients } \\
\hline
\end{tabular}




\begin{tabular}{|l|c|c|}
\hline \multicolumn{1}{|c|}{ DSSI } & $\begin{array}{c}\text { With PO wound } \\
\text { irrigations }\end{array}$ & $\begin{array}{c}\text { Without PO wound } \\
\text { irrigations }\end{array}$ \\
\hline $3^{\text {rd }}$ day \\
\hline Found & $23(6.97 \%)$ & $24(7.24 \%)$ \\
\hline Not found & $307(93.03 \%)$ & $306(92.76 \%)$ \\
\hline $5^{\text {th }}$ day & \multicolumn{2}{|c|}{} \\
\hline Found & $22(6.67 \%)$ & $21(6.37 \%)$ \\
\hline Not found & $308(93.33 \%)$ & $307(93.03 \%)$ \\
\hline $5^{\text {th }}$ day & $21(6.37 \%)$ & $24(7.24 \%)$ \\
\hline Found & $309(93.63 \%)$ & $306(92.76 \%)$ \\
\hline Not found & \multicolumn{2}{|c|}{ Table-IV. Comparison of SSIs on $3^{\text {rd }} 5^{\text {th }} 7^{\text {th }}$ days } \\
\hline \multicolumn{2}{|r|}{} \\
\hline
\end{tabular}

$$
\begin{aligned}
& \text { Chi-Square }=7.787 \quad \text { D.f. }=3 \\
& \text { P-value }=0.079
\end{aligned}
$$

\section{DISCUSSION}

Deep surgical site infections is the most common morbidity found in patients who has treated with laprotomy treatment and it can cause the delay in healing wound, increase in infections, increase in treatment cost and time loss of expertise ${ }^{6}$ due to the long stay at hospital. ${ }^{7}$ In Pakistan, many studies has been conducted to evaluate the frequency of DSSIs and the results shows that rate of surgical site infection (SSIs) are $13 \%,{ }^{8}$ and these results are higher than the western countries. ${ }^{6}$ In USA the SSIs rate is $1.9 \%$. The present proofs is lacking consensus regarding performing of $\mathrm{PO}$ wound irrigation in gastro intestinal method. Previous study shows that DSSIs rate was higher in patients who experienced wound irrigation (31\% vs $9 \%){ }^{3}$

In current research we observed, Out of 330 patients, 180 (54.55\%) were men and 150 (45.45\%) patients were women. 50 (15.15\%) patients having ages of $<20$ years, 110 (33.33\%) patients were aged between 20 to 29 years, 130 (39.39\%) patients were aged between 30 to 39 years, $25(7.58 \%)$ patients having ages of 40 to 49 years and 15 (4.54\%) patients were ages $>49$ years. Hospital stay of patients was recorded from 2 to 10 days, these results showing similarity to the some other studies and it may cause the delay in healing wound, increase in infections, increase in treatment cost and time loss of expertise. ${ }^{7}$ Many other researches shows that an increase duration of hospital stay of patients are 6 to 25 days due to the DSSIs. ${ }^{11-15} 237$ (71.82\%) patients having stay at hospital were 2 to 4 days, $63(19.09 \%)$ patients stay were 5 to 7 days while $30(9.10 \%)$ patients stay were $>7$ days.

In this study, Out of all the 330 patients, 47 (14.24\%) patients found surgical site infections on 3rd days, 43 (13.03\%) found DSSIs on 5th day and $45(13.64 \%)$ patients had deep surgical site infections on 7th day after laparotomy treatment. DSSIs on 3rd days was noted in 23 (6.97\%) patients with Postoperative wound irrigation and $24(7.24 \%)$ without PO wound irrigations, these results were not significant statistically, on fifth day $22(6.67 \%)$ found DSSIs with wound irrigations and $21(6.37 \%)$ without wound irrigations, there is no major difference found, while on 7th day 21 (6.37\%) and 24 (7.24\%) patients had observed deep surgical site infections after operation. No significant differences in SSI rates were observed between the two groups. The overall SSI rate in this single-centre study was comparable to observations of other recent trials (19.6\%)..$^{16-19}$ From these results we concluded that there is no major difference observed in prevalence of SSIs (surgical site infections) whether you performed PO wound irrigations on $5^{\text {th }}$ and $7^{\text {th }}$ day or not performed.

\section{CONCLUSION}

We concluded that there is no major difference observed in prevalence of DSSls whether performing post operative wound irrigation or do not performing $\mathrm{PO}$ wound irrigations after laparotomy procedure. Thus we concluded that the PO wound irrigations is not useful method to decrease the rate of DSSIs on 3rd, 5th and seventh day of after operation.

Copyright@ 20 Oct, 2018.

\section{REFERENCES}

1. Ansari MM, Akhtar A, Haleem S, Husain M, Kumar A. Is there a role of abdominal drainage in primarily repaired perforated peptic ulcers? J Exp Integr Med 2012; 2(1):47-54.

2. Sharma L, Singh A, Bhaskaran S, Radhika AG, Radhakrishnan G. Fallopian tube herniation: an unusual complication of surgical drain. Obstet Gynecol 2012:2012:194350.

3. Mosley JG, Jantet G. Herniation at the site of an 
abdominal drain. Br J Clin Prac 1978; 32(2): 56-8.

4. Malinoski DJ, Patel MS, Yakar DO, Green D, Qureshi F, Inaba K, Brown CV, Salim A. A diagnostic delay of 5 hours increases the risk of death after blunt hollow viscus injury. J Trauma 2010; 69(1):84-7.

5. Reiffel AJ, Barie PS, Spector JA. A multidisciplinary review of the potential association between closedsuction drains and surgical site infection. Surg Infect (Larchmt) 2013; 14(3): 244-69.

6. Yi M, Edwards JR. Improving risk-adjusted measures of surgical site information for the National Healthcare Safety Network. Infect Control Hosp Epidemiol 2011; 2(10):970.

7. Jenks PJ, Laurent M, McQuarry S, Watkins R. Clinical and economic burden of surgical site infection (SSI) and predicted financial consequences of elimination of SSI from an English hospital. J Hosp Infect 2013; 85(1): 24- 3 .

8. Mihaljevic AL, Schirren R, Ozer M, Ottl S, Grun S, Michalski CW, Erkan M,Jager C, Reiser-Erkan C, KehI V, et al. Multicenter double-blindedrandomized controlled trial of standard abdominal wound edge protection with surgical dressings versus coverage with a sterile circular polyethylene drape for prevention of surgical site infections: a CHIR-Net trial (BaFO; NCT01181206). Ann Surg. 2014; 260(5):730-9.

9. Diener MK, Knebel P, Kieser M, Schuler P, Schiergens TS, Atanassov V, Neudecker J, Stein E, Thielemann H, Kunz R, et al. Effectiveness of triclosancoated PDS Plus versus uncoated PDS II sutures for prevention of surgical site infection after abdominal wall closure: The randomised controlled PROUD trial. Lancet. 2014; 384(9938):142-52.

10. Pinkney TD, Calvert M, Bartlett DC, Gheorghe $A$, Redman V, Dowswell G, Hawkins W, Mak T, Youssef H, Richardson C, et al. Impact of wound edge protection devices on surgical site infection after laparotomy: Multicentre randomised controlled trial (ROSSINI Trial). BMJ. 2013; 347:f4305.

11. de Lissovoy G, Fraeman K, Hutchins V, Murphy D, Song $D$, Vaughn BB. Surgical site infection: incidence and impact on hospital utilization and treatment costs. Am J Infect Control. 2009; 37(5):387-97.

12. Barnes S, Spencer M, Graham D, Johnson B. Surgical wound irrigation: A call for evidence-based standardization of practice. Am J Infect control. 2014; 42(5):525-9.

13. Pochhammer J, Weller M-P, Schäffer M. Polihexanide for prevention of wound infection in surgery. Is the contact time essential? POLIS-trial: A historic controlled, clinical pilot trial. Wound Med. 2016; 14:19-24.

14. Sangrasi AK, Leghari AA, Memon A, Talpur K, Qureshi GA, Memon JM. Surgical site infection rate and associated risk factors in elective general surgery at a public sector medical university in Pakistan. Int Wound J 2008; 5:74-8.

15. Talving P, Mohseni S, Inaba K, Plurad D, Branco BC, Lam $\mathrm{L}$, et al. Closed suction drain after isolated hollow viscus injury: A friend or foe? J Trauma 2011; 70(6): 1424-8.

16. Mohseni S, Talving P, Kobayashi L, Kim D, Inaba K, Lam $\mathrm{L}$, et al. Closed-suction drain placement at laparotomy in isolated solid organ injury is not associated with decreased risk of deep surgical site infection. Am Surg 2012; 78(10): 1187-91.

17. Nasir AA, Abdur-Rahman LO, Adeniran JO. Is intraabdominal drainage necessary after laparotomy for typhoid intestinal perforation? J Pediatr Surg 2012; 47(2): 355-8.

18. Mueller TC, Loos M, Haller B, Mihaljevic AL, Nitsche U, Wilhelm D, Friess H, Kleeff J, Bader FG. Intra-operative wound irrigation to reduce surgical site infections after abdominal surgery: A systematic review and meta-analysis. Langenbecks Arch Surg. 2015; 400(2):167-81.

19. Cervantes-Sanchez CR, Gutierrez-Vega R, VazquezCarpizo JA, Clark P, Athie- Gutierrez C. Syringe pressure irrigation of subdermic tissue after appendectomy to decrease the incidence of postoperative wound infection. World J Surg. 2000; 24(1):38-41. discussion $41-2$.

\section{AUTHORSHIP AND CONTRIBUTION DECLARATION}

\begin{tabular}{|c|l|l|}
\hline Sr. \# & \multicolumn{1}{|c|}{ Author-s Full Name } & \multicolumn{1}{|c|}{ Contribution to the paper } \\
\hline 1 & Shahid Hussain Mirani & $\begin{array}{l}\text { Writing of manuscript and } \\
\text { compiling results. }\end{array}$ \\
\hline 2 & Abdul Waheed Khan & $\begin{array}{l}\text { Data collection \& writing of } \\
\text { manuscript. } \\
\text { Statistical analysis \& giodance in } \\
\text { writing the manuscript. }\end{array}$ \\
\hline
\end{tabular}

